\title{
A Case Study of Color Combination Issues in Various Websites
}

\author{
Jatinder Manhas \\ Department of Computer Sc. \& IT, \\ University of Jammu, \\ Baderwah Campus, Baderwah.
}

\author{
Abid Sarwar \\ Department of Computer Sc. \& IT, \\ University of Jammu, \\ Kishtwar Campus, Kishtwar.
}

\begin{abstract}
The growth of web has been exponential. According to a study conducted in May 2005, there were a total of over 11.5 billion pages [1], documents on the World Wide Web, and most of them were in the invisible Web, or Deep Web. Same figure in March 2012 is around 55 billion pages [2]. The size of the web is expanding continuously like the universe after the big bang. The rapid growth of internet for commercial purpose has been noted by many researchers \& practitioners $\&$ it has been almost impossible to escape its growth since its birth in 1990's. The increasing amount of web development work being carried out in these organizations means that such work should be carried out in a well-planned \& systematic manner. In designing Web pages, the background color combination is very important because it has a strong impact on the impression and accessibility of the information [3]. Web accessibility is becoming a prominent issue across the world, not only because of legal and compliance issues, but because of its impact on commercial opportunities [4]. Since the domain of a website is the whole world, we cannot ignore the people who are suffering from various Color impairments. An essential part of web design today is designing it in a way that it is equally viable to the individuals with limited abilities [5]. As such a website should be built in such a way as is equally accessible to all the people around the world - of all ages and abilities. The aim of the paper is to analyze the websites in order to check their accessibility to colorblind community. For the sake of study authors have selected a set of websites i.e websites of the various Universities in Jammu \& Kashmir. The web sites of the universities are among the most accessed websites which involve heavy web traffic as such must be developed in such a manner that the format and design for the same be equally accessible and viable to the Color blind community as well.
\end{abstract}

\section{General Terms}

Web Design Issues

\section{Keywords}

Colorblindness, Web Design Issues, Color-contrast ratio,W3C

\section{INTRODUCTION}

Development of websites is becoming a growing concern among all the organizations around the globe. According to an estimate in 1993 the World Wide Web carried only one percent of the information flowing through duplex communication mode, by 2000 it grew to 51 percent and by 2007 figure became 97 percent [6]. Access to such a huge amount of information on the internet should be impartial to the masses across the world. World Wide Web Consortium (W3C) in May 1999 published Web Content Accessibility
Guidelines 1.0, and the same was replaced with Web Content Accessibility Guidelines 2.0 in December 2008[7]. The main aim of these guidelines is to make the content on the World Wide Web accessible to a wider range of people with disabilities, including Colorblindness, complete blindness and low vision, deafness and hearing loss, learning disabilities, cognitive limitations, limited movement, speech disabilities, photosensitivity and combinations of these. Color blindness, also known as Color vision confusion is an abnormal condition of vision wherein the subject is incapable to differentiate between various Colors of the spectrum [8]. A person suffering from Color blindness is not blind but can see limited range of Colors. It has nothing to do with eyesight many people consider that the Colorblind people are devoid of seeing all the Colors and can see any black \& white Color which is not true. Color blindness is mostly neglected \& most people do not consider this to be a serious issue. However, the effects of Color blindness can be severe. The problem of Color blindness has been found to be more prominent among male than in females. Of all the people suffering from Color blindness in United States (US), more than $8 \%$ are males \& between $0.4 \%$ to $2 \%$ are females. The Color blindness can be of following types: 1. Monochromic (complete Colorblindness / total Color blindness). 2. Dichromacy (person suffering from dichromacy can match any Color they see with some mixture of only two spectral lights (whereas a normal person needs three spectral lights for proper Color vision). Dichromacy has 3 types a. Protanopia (a person having Protanopia cannot make difference between Red, Yellow \& Orange in the spectrum) b. Deuteranopia ( a person having deuteranopia cannot make difference between Red, Yellow \& Green in the spectrum) \& c. Tritanopia (a person having tritanopia cannot make difference between Blue \& Yellow. It is also called as Blue-Yellow Color blindness). 3. Anomalous Trichromacy: A person who suffers from Anomalous Trichromacy makes Color matches which differ from normal persons. It is of following types: a. Protanomaly: persons who suffer from protanomaly are less sensitive to red Color \& need excessive amount of red Color in order to identify the redgreen mixture than normal persons. b. Deuteranomaly: persons who suffer from protanomaly are less sensitive to green Color and need excessive amount of green Color in order to identify the red- green mixture. c. Tritanomaly: this form of Anomalous Trichromacy is rarely found.

\section{PROBLEM IDENTIFICATION}

According to the Web Content Accessibility Guidelines WCAG 2.0 (1.4.3), regarding the minimum contrast ratio, the permissible Color contrast ratio of text and images of text should be at least 4.5:1. Similarly 1.4.6 guidelines regarding the enhanced contrast ratio, the permissible Color contrast ratio of text and images of text should be at least 7:1 [7]. On 
analyzing the various websites the authors found the websites violating the standard rules. Learning \& vision go side by side. The senses of sight play a critical role for the acquisition of knowledge. In a study it was found that roughly $80 \%$ of the knowledge that is acquired by a student is the information which is presented through the sense of sight. So the dissemination through the websites can be fully achieved if the $\mathrm{W} 3 \mathrm{C}$ rules are followed properly. The websites of all the universities in Jammu \& Kashmir were analyzed \& it was

found that all the websites are violating the rules in one way or the other. The study indicates that the websites of all the universities in Jammu \& Kashmir have significant design errors as far as the permissible Color combinations are concerned. Such poorly developed websites which are mushrooming now-a-days and have high probability of low performance or failure. This propagates lack of confidence in the web and ultimately it leads to Web-Crisis [9]. As a result of which the people suffering from various visual impairments find it difficult to retrieve information from these websites.

\section{RESEARCH METHODOOGY}

The methodology used for research was case study. A case study is a process of research in which detailed consideration is given to a particular phenomenon within its real life context, supported by multiple sources of evidences. The sample data for the studies undertaken in this paper constitutes of the websites of all the universities in the state of Jammu and Kashmir. Since the universities are considered to be the topmost centers of knowledge and excellence, a critical analysis of their websites shall be the reflection of the performance evaluation of other websites in the region too. Authors used the various online tools to evaluate various color combinations of the websites under consideration. The results of the case study are summarized in Table-I.

\section{RESULTS AND DISCUSSIONS}

Authors evaluated the websites of the domain under consideration across the online tool (www.checkmycolors.com ) for three factors viz Luminosity Contrast Ratio, Brightness Difference \& Color Difference. Luminosity contrast ratio is the difference between the brightest Colors to that of the darkest Color that the system is capable of producing. It is a desirable aspect to have a greater value of Luminosity contrast ratio. The brightness difference and the Color difference are the two parameters that are used to ensure good visibility of content over the webpage. The minimum value of brightness difference, Color difference as permitted by guidelines is 500 . Color brightness is determined by the following formula: $\{((\operatorname{Red}$ value $X 299)+$ (Green value X 587) + (Blue value X 114)) / 1000\} and Color difference is determined by the following formula: \{ (maximum (Red value 1, Red value 2) - minimum (Red value 1$, Red value 2$))+($ maximum $($ Green value 1 , Green value 2$)$ - minimum (Green value 1, Green value 2)) + (maximum (Blue value 1, Blue value 2) - minimum (Blue value 1, Blue value 2)) $\}$. The online tool does after analysis of the various elements of the web pages points out the errors in all these factors. The results of the study were analyzed and it was found that and found that the website of the Central University of Kashmir (www.cukashmir.ac.in) had the minimum percentage $(55.55 \%)$ of failure and was followed by the website of Baba Ghulam Shah Badshah University of Agriculture Science and Technology Kashmir (SKUAST) ) ( www.skuastkashmir.ac.in)(68.22\%), University of Kashmir (www.kashmiruniversity.net) $(88.57 \%)$, University of Jammu(www.jammuuniversity.in) $\quad(97.70 \%), \quad$ Islamic University Sc. \& Technology (www.islamicuniversity.edu.in) (107.00\% ), Sher-e-Kashmir Agriculture University Jammu (SKUAST) ( www.skuast.org/new/index.html)(113.24\%), Central University of Jammu(www.cujammu.in)(126.54\%) \& last by Shri. Mata Vaishno Devi University (www.smvdu.net.in) (144.87\%).

Table 1: Colour Combination Errors

\begin{tabular}{|c|c|c|c|c|c|c|}
\hline $\begin{array}{l}\text { S. } \\
\text { No }\end{array}$ & Name of the University & $\begin{array}{l}\text { No. of } \\
\text { Elements }\end{array}$ & $\begin{array}{c}\text { Luminosity } \\
\text { Contrast } \\
\text { Ratio failures } \\
\end{array}$ & $\begin{array}{c}\text { Brightness } \\
\text { Difference } \\
\text { failures }\end{array}$ & $\begin{array}{c}\text { Colour } \\
\text { Difference } \\
\text { Failures } \\
\end{array}$ & $\begin{array}{c}\% \text {-age of } \\
\text { errors }\end{array}$ \\
\hline 1. & $\begin{array}{l}\text { University of Jammu } \\
\text { (www.jammuuniversity.in ) }\end{array}$ & 757 & 242 & 237 & 256 & $97.70 \%$ \\
\hline 2 & $\begin{array}{l}\text { University of Kashmir } \\
\text { (www.kashmiruniversity.net ) }\end{array}$ & 35 & 5 & 5 & 21 & $88.57 \%$ \\
\hline 3 & $\begin{array}{l}\text { Islamic University of Sc. \& Technology } \\
\text { (www.islamicuniversity.edu.in ) }\end{array}$ & 51 & 12 & 6 & 37 & $107.00 \%$ \\
\hline 4 & $\begin{array}{l}\text { Baba Ghulam Shah Badhshsh University } \\
\text { (www.bgsbuniversity.org ) }\end{array}$ & 351 & 71 & 72 & 72 & $61.25 \%$ \\
\hline 5 & $\begin{array}{l}\text { Shri Mata Vaisho Devi University } \\
\text { (www.smvdu.net.in ) }\end{array}$ & 441 & 211 & 211 & 211 & $143.53 \%$ \\
\hline 6 & $\begin{array}{l}\text { Central University of Jammu } \\
\text { (www.cujammu.in ) }\end{array}$ & 113 & 44 & 39 & 60 & $126.54 \%$ \\
\hline 7 & $\begin{array}{l}\text { Central University of Kashmir } \\
\text { ( www.cukashmir.ac.in ) }\end{array}$ & 612 & 63 & 135 & 142 & $55.55 \%$ \\
\hline 8 & $\begin{array}{l}\text { SKUAST Kashmir } \\
\text { (www.skuastkashmir.ac.in ) }\end{array}$ & 343 & 52 & 51 & 131 & $68.22 \%$ \\
\hline 9 & $\begin{array}{l}\text { SKUAST Jammu } \\
\text { (www.skuast.org/new/index.html ) }\end{array}$ & 219 & 82 & 82 & 84 & $113.24 \%$ \\
\hline
\end{tabular}




\section{CONCLUSION}

The investigations carried out in this paper site sufficient region to state that the websites of almost all the universities of Jammu \& Kashmir are neglecting guidelines approved and recommended for the development of the websites by W3C. As a result of which these websites are not properly visible to the people suffering for color blindness. It is clear in our research that more efforts are required to meet with these criteria in the context of website design. Authors suggest that web developer community should be encouraged the use of recommended guidelines when designing websites. Further the organizations for which the websites are developed must also be educated regarding the standards to be followed and the pros \& cons of ignoring them. Not only this, the standards framed for the design and development should be widely circulated among various institutions.

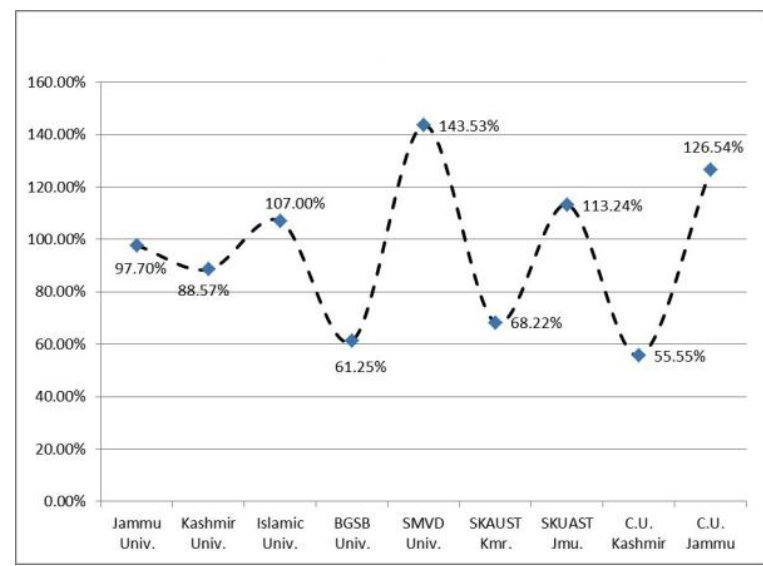

Figure 1: Percentage of Errors

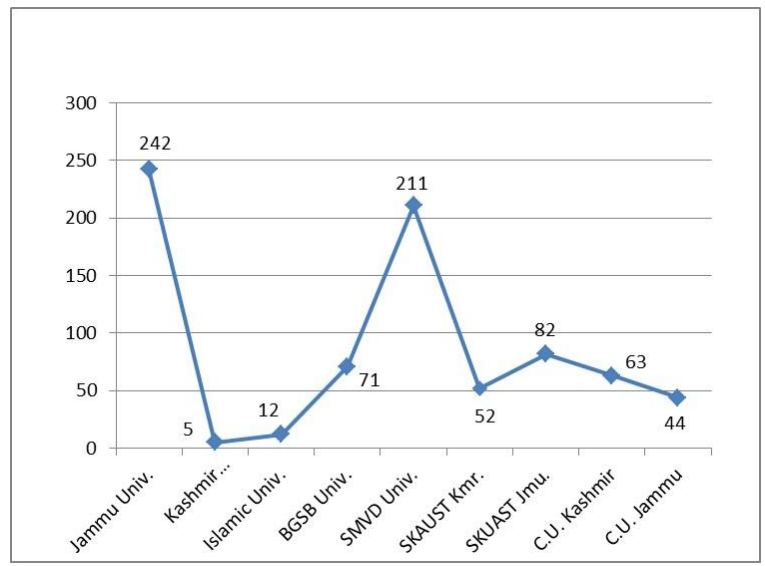

Figure 2: Luminosity Contrast Ratio Failures

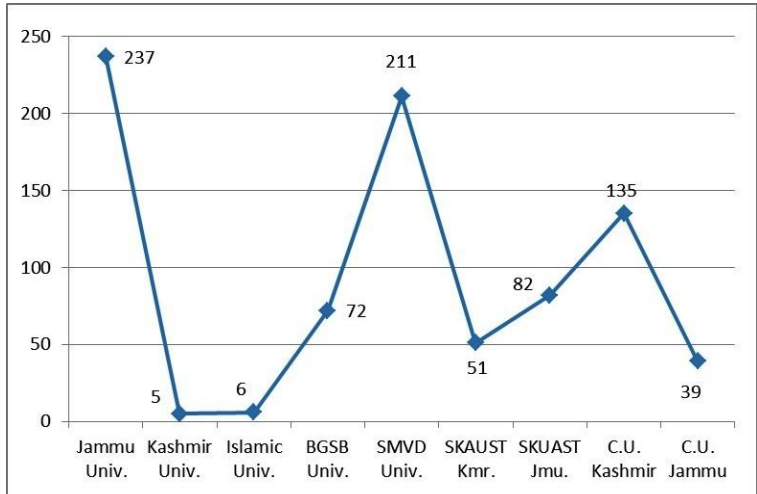

Figure 3:Brightness Difference Failures

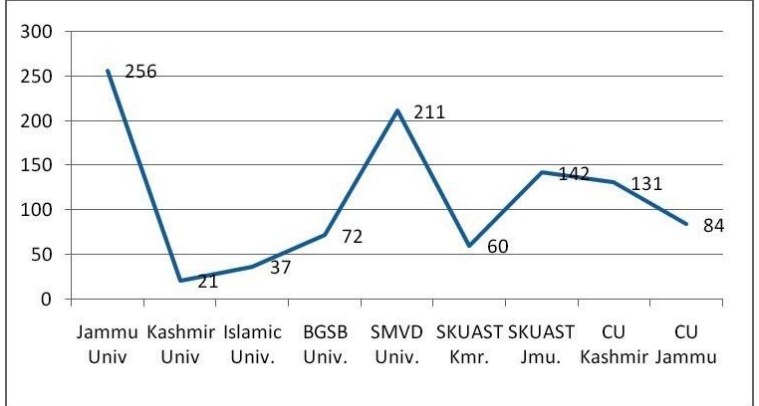

Figure 4: Color Difference Failures

\section{FUTURE SCOPE}

As a future work a larger set of websites can be evaluated for permissible color combinations. Other parameters like download speed, website composition, text font size etc. can also be taken into consideration for evaluating them against the $\mathrm{W} 3 \mathrm{C}$ guidelines. Other perspective like the impact of browsers on making the website content viable to physically challenged community can also be evaluated. Moreover the ultimate determinant of quality website is the user; as such future directions for this research can also involve the objective and subjective views regarding problems encountered from user's perspective

\section{ACKNOWLEDGMENTS}

This paper has benefited by the discussions with people in the area of web development, web users and academicians up to a greater extent

\section{ACKNOWLEDGMENTS}

Our thanks to the experts who have contributed towards development of the template.

\section{REFERENCES}

[1] The indexable web is more than 11.5 billion pages, A.Gulli \& A.Signorini, ACM 1-59593-051-5/05/0005, Chiba, Japan

[2] http://www.worldwidewebsize.com

[3] Ueki, H, Azuma, M.,Background color coordination support system for Web Page design, Cognitive Informatics, 2003. Proceedings. The Second IEEE International Conference

[4] Development of Automatic Web Accessibility Checking Modules for Advanced Quality Assurance Tools

[5] Foley, A. \& Regan, B. (2002). Web Design for Accessibility: Policies and Practice. AACE Journal, 10(1), 62-80. Norfolk, VA: AACE

[6] http://4c- comm.com/blog/2011/11/28/unpacking-thecloud-today-tomorrow-and-beyond/

[7] Web Content Accessibility Guidelines 2.0, March 2004(http://www.w3.org/TR/2008/REC-WCAG2020081211/)

[8] "The eye of the beholder"-Designing for the Color blind users. British Telecommunication Engineering, Vol. 17, Jan. 1999. Christine Rigden

[9] Zelnic, N.Nifty, Technology and non- conformance. TheWeb Crisis, October 1998 pp115-116 \&119 Zelnic, N.Nifty, Technology and non- conformance. TheWeb Crisis, October 1998 pp115-116 \&119 